\section{OPEN ACCESS}

Edited by:

Simone Frediani,

Bambino Gesù Children Hospital (IRCCS), Italy

Reviewed by:

Nick Zavras,

University General Hospital

Attikon, Greece

Ernesto Leva,

University of Milan, Italy

*Correspondence:

Gunadi

drgunadi@ugm.ac.id

Specialty section:

This article was submitted to

Pediatric Surgery,

a section of the journal

Frontiers in Pediatrics

Received: 20 July 2021

Accepted: 15 September 2021

Published: 20 October 2021

Citation:

Siahaan ESED, Adriansyah W Sasmita AP, Fauzi AR, Dwihantoro $A$ and Gunadi (2021) Outcomes and Prognostic Factors for Survival of

Neonates With Necrotizing

Enterocolitis. Front. Pediatr. 9:744504.

doi: 10.3389/fped.2021.744504

\title{
Outcomes and Prognostic Factors for Survival of Neonates With Necrotizing Enterocolitis
}

\section{Elena Sophia Elekta Dilean Siahaan, Wahyudhy Adriansyah, Andika Purba Sasmita, Aditya Rifqi Fauzi, Andi Dwihantoro and Gunadi*}

Pediatric Surgery Division, Department of Surgery, Faculty of Medicine, Public Health and Nursing, Universitas Gadjah Mada/Dr. Sardjito Hospital, Yogyakarta, Indonesia

Background: Due to the survival of preterm neonates being continually improved, the modifiable prognostic factors of necrotizing enterocolitis (NEC) are essential to be investigated and considered in making a suitable treatment to decrease the prevalence and effect of NEC. Many prognostic factors have been associated with the survival of neonates with NEC; however, the studies show conflicting results. Moreover, the study from developing countries regarding NEC outcomes is minimal. Here, we aimed to determine the survival of neonates with NEC and associate it with the prognostic factors.

Methods: A retrospective study was conducted using medical records of neonates with NEC at our institution from January 2014 to December 2019.

Results: Fifty-two neonates with NEC were involved with the overall survival of $44.2 \%$. Log-rank analysis showed that NEC staging and birth weight were significantly associated with the survival of neonates with NEC with a $p$-value of 0.010 and 0.002 , respectively, while sex, APGAR score, platelet count, and type of treatment were not $(p=0.068,0.752,0.087$, and 0.343 , respectively). Multivariate analysis revealed that sex and NEC staging were strongly associated with the survival of neonates with NEC with a $p$-value of $0.018[\mathrm{HR}=3.10(95 \% \mathrm{Cl}=1.21-7.93)]$ and $0.019[\mathrm{HR}=0.44$ (0.22-0.87)], respectively.

Conclusions: Our study shows that sex and NEC staging might affect the survival of neonates with NEC. It implies that NEC staging should be closely monitored and intervened as early as necessary to prevent further morbidity and mortality.

Keywords: developing country, necrotizing enterocolitis, prognostic factors, NEC staging, survival

\section{INTRODUCTION}

Necrotizing enterocolitis (NEC) is the leading cause of morbidity and mortality of neonates with intestinal disorders in the neonatal intensive care unit (NICU) (1). Its incidence is 1 per 1,000 live births, and more than $90 \%$ of cases are premature infants (2). Its incidence is increasing because of the increasing number of preterm birth and the advances in neonatal care $(3,4)$.

Due to the continually improving survival of preterm neonates, the modifiable prognostic factors of NEC are essential to be investigated and considered in making a suitable treatment to decrease the prevalence and effect of NEC (4). Many prognostic factors have been associated with 
the survival of neonates with NEC; however, the studies show conflicting results $(1,5,6)$. Moreover, the study from developing countries regarding NEC outcomes is minimal $(7,8)$. Here, we aimed to determine the survival of neonates with NEC and associate it with the prognostic factors.

\section{METHODS}

\section{Subjects and Necrotizing Enterocolitis Staging}

A retrospective study was conducted using medical records of neonates with NEC at our institution from January 2014 to December 2019. We included 56 diagnosed with NEC, with the International Classification of Diagnosis (ICD) X code of P.77. According to modified Bell's staging, the diagnosis and staging of NEC were established, consisting of the severity of systemic, intestinal, radiographic, and laboratory findings (9). The exclusion criteria were incomplete medical records. We excluded four neonates due to incomplete medical records and investigated 52 neonates for final analysis.

The Ethical Committee of the Faculty of Medicine, Universitas Gadjah Mada/Dr. Sardjito Hospital, Indonesia, approved the study (KE/FK/0375/EC/2020).

\section{Prognostic Factors}

We evaluated the following prognostic factors for the survival of neonates with NEC: sex, birth weight, NEC staging, platelet count, APGAR score, and type of treatment. Birth weight was classified into extremely low birth weight $(<1,000 \mathrm{~g})$, very low birth weight $(<1,500 \mathrm{~g})$, low birth weight $(<2,500 \mathrm{~g})$, and normal $(\geq 2,500 \mathrm{~g})$ according to World Health Organization classification, while the platelet count was defined as thromb ocytosis $\left(>350,000 / \mathrm{mm}^{3}\right)$, normal $\left(\geq 150,000-350,000 / \mathrm{mm}^{3}\right)$, and thrombocytopenia $\left(<150,000 / \mathrm{mm}^{3}\right)$ according to a previous study (6). The type of treatment is divided into conservative and surgical procedures, while the APGAR Score was classified as asphyxia $(<8)$ and non-asphyxia $(\geq 8)$.

\section{Enteral Feeding}

The decision to start enteral feeding was according to the following parameters: bowel sounds, no greenish gastric residual, and the volume of gastric residual was $<1 \mathrm{ml} / \mathrm{kg} /$ day. Most of the enteral feeding was breastfeeding (94.2\%) (Table 1).

\section{Statistical Analysis}

The survival of neonates with NEC was determined using a logrank test, while the probabilities of the survival of the neonates were plotted using the Kaplan-Meier curve. The IBM SPSS Statistics version 16 (SPSS Chicago, IL, USA) was utilized to perform all statistical analyses.

Abbreviations: APGAR, appearance pulse grimace activity respiration; CI, confidence interval; HR, hazard ratio; NEC, necrotizing enterocolitis; NICU, neonatal intensive care unit.
TABLE 1 | Baseline characteristics of neonates with NEC in our institution.

\begin{tabular}{|c|c|}
\hline Characteristics & $N(\%)$ \\
\hline \multicolumn{2}{|l|}{ Sex } \\
\hline Male & $29(55.8)$ \\
\hline Female & $23(44.2)$ \\
\hline \multicolumn{2}{|l|}{ Asphyxia (APGAR score) } \\
\hline Yes $(<8)$ & $27(51.9)$ \\
\hline No $(\geq 8)$ & $25(48.1)$ \\
\hline \multicolumn{2}{|l|}{ Birth weight (g) } \\
\hline Normal birth weight $(\geq 2,500)$ & $12(23)$ \\
\hline Low birth weight $(<2,500)$ & $20(38.5)$ \\
\hline Very low birth weight $(<1,500)$ & $17(32.7)$ \\
\hline Extremely low birth weight $(<1,000)$ & $3(5.8)$ \\
\hline \multicolumn{2}{|l|}{ Platelet count $\left(/ \mathrm{mm}^{3}\right)$} \\
\hline Thrombocytosis $(>350,000)$ & $6(11.5)$ \\
\hline Normal $(\geq 150,000-350,000)$ & $20(38.5)$ \\
\hline Thrombocytopenia $(<150,000)$ & $26(50)$ \\
\hline \multicolumn{2}{|l|}{ NEC staging } \\
\hline IA & $18(34.6)$ \\
\hline IB & $2(3.9)$ \\
\hline$\| \mathrm{A}$ & $15(28.9)$ \\
\hline IIB & 0 \\
\hline$\| I I A$ & $7(13.4)$ \\
\hline IIIB & $10(19.2)$ \\
\hline \multicolumn{2}{|l|}{ Type of treatment } \\
\hline Conservative & $39(75)$ \\
\hline Operative & $13(25)$ \\
\hline \multicolumn{2}{|l|}{ Feeding } \\
\hline Breastfeeding & $49(94.2)$ \\
\hline Formula & $3(5.8)$ \\
\hline \multicolumn{2}{|l|}{ Sepsis } \\
\hline Yes & $48(92.3)$ \\
\hline No & $4(7.7)$ \\
\hline \multicolumn{2}{|l|}{ Mechanical ventilation } \\
\hline PCAC & $4(7.7)$ \\
\hline PCMV & $15(28.8)$ \\
\hline SIMV & $2(3.8)$ \\
\hline NIMV & $4(7.7)$ \\
\hline CPAP & $10(19.2)$ \\
\hline \multicolumn{2}{|l|}{ Survival } \\
\hline Survived & $23(44.2)$ \\
\hline - Male & $14(60.9)$ \\
\hline - Female & $9(39.1)$ \\
\hline Died & $29(55.8)$ \\
\hline - Male & $14(48.3)$ \\
\hline - Female & $15(51.7)$ \\
\hline
\end{tabular}

NEC, necrotizing enterocolitis.

\section{RESULTS}

\section{Baseline Characteristics}

We involved 52 neonates with NEC with overall survival of $44.2 \%$. Most of them were male (55.8\%), with asphyxia (51.9\%), low birth weight or less (77\%), thrombocytopenia (50\%), sepsis (92.3\%), and breastfeeding (94.2\%) (Table 1). 


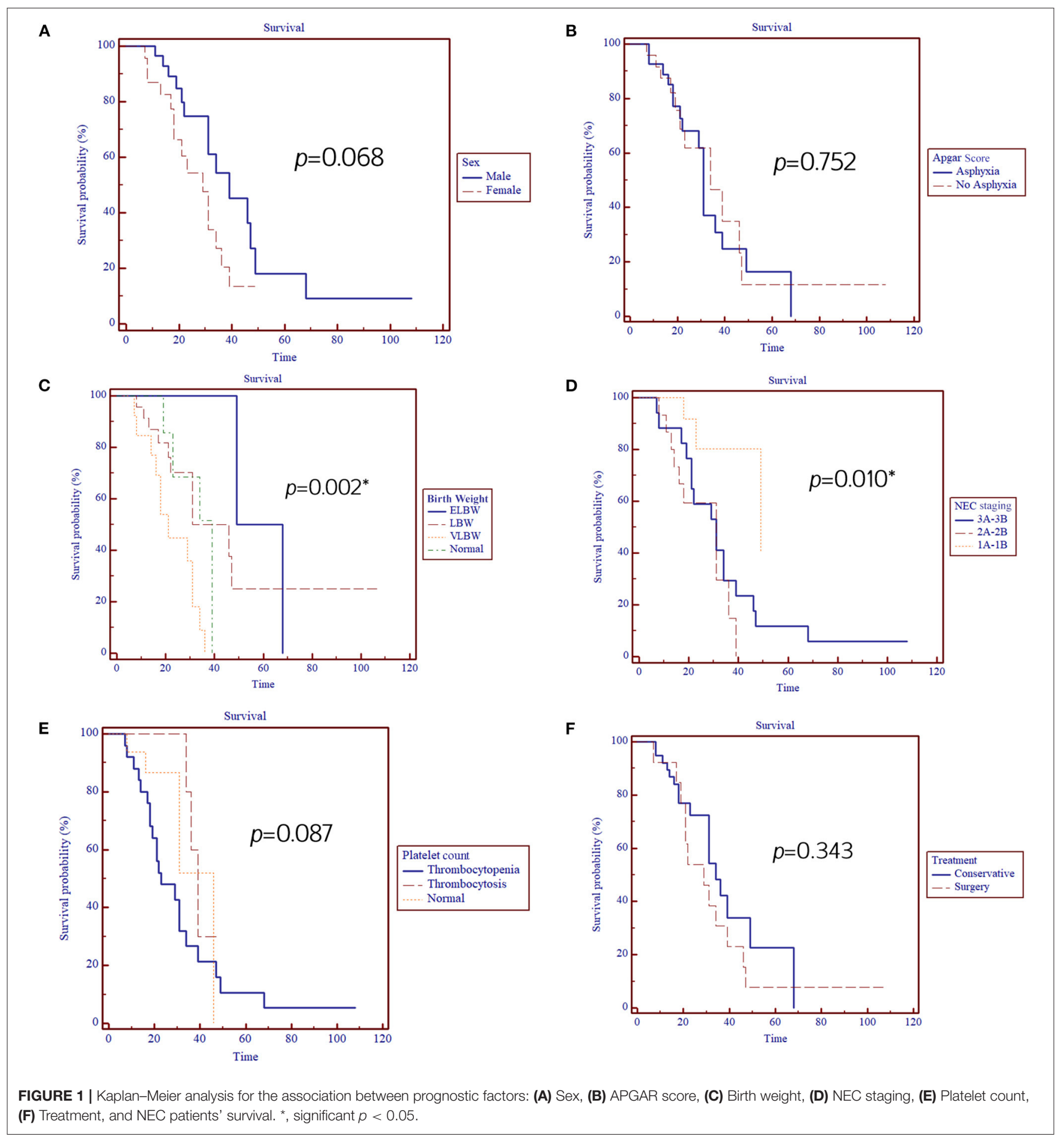

Association Between Prognostic Factors and Survival of Neonates With Necrotizing Enterocolitis

Log-rank analysis showed that NEC staging and birth weight were significantly associated with the survival of neonates with NEC with a p-value of 0.010 and 0.002, respectively. At the same time, sex, APGAR score, platelet count, and type of treatment were not $(p=0.068,0.752,0.087$, and 0.343 , respectively)

(Figure 1; Table 2). 
TABLE 2 | Association between prognostic factors and survival of neonates with NEC in our institution.

\begin{tabular}{|c|c|c|}
\hline Variables & HR (95\% Cl) & $p$-Value \\
\hline \multicolumn{3}{|l|}{ Sex } \\
\hline Female & $1.89(0.89-4.04)$ & 0.068 \\
\hline \multicolumn{3}{|l|}{ Asphyxia } \\
\hline APGAR score $<8$ & $1.12(0.54-2.34)$ & 0.752 \\
\hline \multicolumn{3}{|c|}{ Birth weight (Ref: normal birth weight) } \\
\hline Low birth weight & $0.87(0.33-2.32)$ & $0.002^{\star}$ \\
\hline Very low birth weight & $2.75(0.83-9.13)$ & \\
\hline Extremely low birth weight & $0.45(0.14-1.46)$ & \\
\hline \multicolumn{3}{|c|}{ Platelet count (Ref: Normal) } \\
\hline Thrombocytopenia & $1.84(0.75-4.53)$ & 0.087 \\
\hline Thrombocytosis & $0.62(0.21-1.80)$ & \\
\hline \multicolumn{3}{|l|}{ NEC staging (Ref: IA-IB) } \\
\hline$\|\mathrm{A}-\| \mathrm{B}$ & $5.83(2.07-16.40)$ & $0.010^{\star}$ \\
\hline$\|\mathrm{A}-\| \mathrm{II}$ & $3.89(1.71-8.84)$ & \\
\hline \multicolumn{3}{|l|}{ Type of treatment } \\
\hline Surgery & $1.41(0.65-3.05)$ & 0.343 \\
\hline
\end{tabular}

TABLE 3 | Multivariate analysis of survival of neonates with NEC in our institution.

\begin{tabular}{lcc}
\hline Variables & HR (95\% Cl) & p-value \\
\hline Sex (female) & $3.10(1.21-7.93)$ & $0.018^{\star}$ \\
Asphyxia & $1.04(0.36-2.98)$ & 0.940 \\
Birth weight & $1.41(0.82-2.41)$ & 0.211 \\
Platelet count & $1.94(0.93-4.06)$ & 0.079 \\
NEC staging & $0.44(0.22-0.87)$ & $0.019^{\star}$ \\
Type of treatment & $1.84(0.54-6.34)$ & 0.332 \\
\hline
\end{tabular}

${ }^{*} \mathrm{p}<0.05 ; \mathrm{Cl}$, confidence interval; HR, hazard ratio; NEC, necrotizing enterocolitis.

\section{Multivariate Analysis of Prognostic Factors for Survival of Neonates With Necrotizing Enterocolitis}

Multivariate analysis revealed that sex (female) and NEC staging were strongly associated with the survival of neonates with NEC with $a p$-value of 0.018 hazard ratio $[\mathrm{HR}]=3.10[95 \%$ confidence interval $(\mathrm{CI})=1.21-7.93]\}$ and $0.019[\mathrm{HR}=0.44$ $[95 \% \mathrm{CI}=0.22-0.87)]$, respectively (Table 3 ).

\section{DISCUSSION}

Here, we show that the overall survival of our NEC neonates is $44.2 \%$, which is similar to a previous study (10). One reason for the high mortality rate was withdrawal from critical care, while another reason was the unavailability of pediatric surgery services in some hospitals; thus, surgery was not possible (10). Our institution, as an academic referral hospital, has pediatric surgery services. However, our findings were not compatible with a previous report (10) since the type of treatment did not affect the outcome of NEC infants (Table 3).

We reveal that NEC staging is a strong prognostic factor for the survival of neonates with NEC. Our findings were compatible with a previous study that revealed that the NEC stage III in VLBW and LBW infants is an independent prognostic factor for the survival of neonates with NEC (7). Moreover, lower birth weight was significantly associated with NEC incidence and mortality $(11,12)$. Immaturity of the gastrointestinal tract, digestive function, circulation regulation, barrier function, and immune defense are essential factors in explaining NEC occurring in infants with LBW (13). We show new evidence to support this hypothesis by providing data from a population ethnically different from the previous report (7). The previous report showed that the prognostic factors for NEC had been expanded, including ethnicity (4). Moreover, due to the survival of preterm neonates being continually improved, it is suggested that clinicians and researchers should look for the prognostic factors for NEC, particularly the modifiable one, to be taken into consideration in making a suitable treatment to decrease the prevalence and effect of NEC (4).

Interestingly, female patients had a 3.1-fold higher risk of mortality than male patients. A previous study showed that male is a risk factor for mortality (11). These differences might be due to different ethnicities. Ethnicity has been considered as a prognostic factor for NEC (4). In addition, a previous study showed no association between sex and NEC (9). They suggested continuous assessment on the impact of sex on the severity of NEC since the male has tended to suffer from NEC (9).

Our study presented that thrombocytopenia almost reached a significant level affecting the mortality of NEC infants with the HR of $\sim 2(p=0.07)$ (Table 3). Most neonates with advanced stages of NEC will have thrombocytopenia within $24-72 \mathrm{~h}$ of disease onset (14). Thrombocytopenia level is strongly correlated with the clinical staging of NEC, and a progressive decrease in thrombocyte level implies the development of intestinal gangrene (15). In addition, thrombocytopenia has been shown as a strong predictor of the mortality of neonates with NEC (16).

Treatment type is a significant prognostic factor in NEC patients (17). Infants with NEC who underwent surgery had higher morbidity and mortality than those who received conservative treatment $(17,18)$. However, our findings showed that type of treatment did not affect the mortality of NEC neonates. While Hull et al. (19) revealed that different surgical approaches affected the mortality of NEC neonates, none of the specific surgical approaches is suggested for NEC (19). It depends on several variables, including the birth weight, hemodynamic status, comorbidities, existing resources, intraoperative findings, and attending physician preference of the neonate (19).

Our study noted several limitations, including a small sample size and a single-center report, implying that a further multicenter study with larger sample size is necessary to clarify and confirm our findings. These weaknesses should be noted during the interpretation of our findings. Due to its retrospective design, we have difficulty evaluating the longterm complications of NEC, including neurodevelopmental impairment, poor growth, gastrointestinal sequels, such as 
strictures, adhesions, feeding difficulties, cholestasis, short bowel syndrome, and intestinal failure (20).

\section{CONCLUSION}

Our study shows that sex and NEC staging might affect the survival of neonates with NEC. It implies that NEC staging should be closely monitored and intervened as early as necessary to prevent further morbidity and mortality.

\section{DATA AVAILABILITY STATEMENT}

The original contributions presented in the study are included in the article/supplementary material, further inquiries can be directed to the corresponding author/s.

\section{ETHICS STATEMENT}

The studies involving human participants were reviewed and approved by Faculty of Medicine, Public Health and

\section{REFERENCES}

1. Samuels N, van de Graaf RA, de Jonge RCJ, Reiss IK, Vermeulen MJ. Risk factors for necrotizing enterocolitis in neonates: a systematic review of prognostic studies. BMC Pediatr. (2017) 17:105. doi: 10.1186/s12887-017-0847-3

2. Stoll BJ, Hansen NI, Bell EF, Shankaran S, Laptook AR, Walsh MC, et al. Neonatal outcomes of extremely preterm infants from the NICHD neonatal research network. Pediatrics. (2010) 126:443-56. doi: 10.1542/peds.2009-2959

3. Sylvester KG, Liu GY, Albanese CT. Necrotizing enterocolitis. In: Coran AG, Caldamone A, Adzick NS, Krummel TM, Laberge JM, Shamberger R, editors. Pediatric Surgery. Philadelphia, PA: 7th ed. Elsevier Saunders (2012). p. 1187-207.

4. Alsaied A, Islam $\mathrm{N}$, Thalib L. Global incidence of necrotizing enterocolitis: a systematic review and meta-analysis. BMC Pediatr. (2020) 20:344. doi: 10.1186/s12887-020-02231-5

5. Clark RH, Gordon P, Walker WM, Laughon M, Smith PB, Spitzer AR. Characteristics of patients who die of necrotizing enterocolitis. J Perinatol. (2012) 32:199-204. doi: 10.1038/jp.2011.65

6. Bracho-Blanchet E, Torrecilla-Navarrete ME, Zalles-Vidal C, Ibarra-Ríos D, Fernández-Portilla E, Dávila-Pérez R. Prognostic factors related to mortality in newborns with necrotising enterocolitis. Cirugía y Cirujanos. (2015) 83:286-91. doi: 10.1016/j.circen.2015.09.015

7. Bora R, Murthy NB. In resource limited areas complete enteral feed in stable very low birth weight infants (1000-1500 g) started within $24 \mathrm{~h}$ of life can improve nutritional outcome. J Matern Fetal Neonatal Med. (2017) 30:2572-7. doi: 10.1080/14767058.2016.12 56992

8. Satardien M, Van Wyk L, Sidler D, Van Zyl JI. Outcomes of neonates requiring neonatal intensive care admission for necrotizing enterocolitis in a resource-restricted hospital in Cape Town, South Africa. J Trop Pediatr. (2021) 67:fmaa130. doi: 10.1093/tropej/fma a130

9. Kim JH. Neonatal necrotizing enterocolitis: clinical features and diagnosis. In: UpToDate, Abrams SA, Kim MS, editors. UpToDate. Waltham, MA (2021) Available online at: https://www.uptodate.com/contents/search (accessed on March 31, 2021).

10. Qian T, Zhang R, Zhu L, Shi P, Yang J, Yang CY, et al. Necrotizing enterocolitis in low birth weight infants in China: Mortality risk factors expressed by birth weight categories.
Nursing, Unversitas Gadjah Mada/Dr. Sardjito Hospital. Written informed consent to participate in this study was provided by the participants' legal guardian/next of kin.

\section{AUTHOR CONTRIBUTIONS}

AD and G conceived the study. ESEDS, WA, APS, ARF, and G drafted the manuscript. ESEDS and $G$ analyzed the data. AD and $G$ facilitated all project-related tasks. All authors read and approved the final manuscript.

\section{ACKNOWLEDGMENTS}

We extend our thanks to Henggar Allest Pratama who provided excellent technical support and assistance during the study. We are also thankful to the English editing service staff at the Faculty of Medicine, Public Health and Nursing, Universitas Gadjah Mada, for checking the manuscript grammar. Some results for the manuscript are from ESEDS's thesis.
Pediatr Neonatol. (2017) 58:509-15. doi: 10.1016/j.pedneo.2016.1 0.004

11. Yeo SL. NICU update: state of the science of NEC. J Perinat Neonatal Nurs. (2006) 20:46-50. doi: 10.1097/00005237-200601000-0 0016

12. Stapleton TD, Kahn JM, Evans LE, Critchlow CW, Gardella CM. Risk factors for group B streptococcal genitourinary tract colonization in pregnant women. Obstet Gynecol. (2005) 106:1246-52. doi: 10.1097/01.AOG.0000187893.524 $88.4 \mathrm{~b}$

13. Lin HY, Chang JH, Chung MY, Lin HC. Prevention of necrotizing enterocolitis in preterm very low birth weight infants: is it feasible? J Formos Med Assoc. (2014) 113:490-7. doi: 10.1016/j.jfma.2013.0 3.010

14. Song R, Subbarao GC, Maheshwari A. Haematological abnormalities in neonatal necrotizing enterocolitis. J Matern Fetal Neonatal Med. (2012) 25(supple. 4):14-7. doi: 10.3109/14767058.2012.71 5005

15. Ververidis M, Kiely EM, Spitz L, Drake DP, Eaton S, Pierro A. The clinical significance of thrombocytopenia in neonates with necrotizing enterocolitis. J Ped Surg. (2001) 36:799-803. doi: 10.1053/jpsu.2001.2 2964

16. Kenton AB, Hegemier S, Smith EO, O’Donovan DJ, Brandt ML, Cass DL, et al. Platelet transfusions in infants with necrotizing enterocolitis do not lower mortality but may increase morbidity. J Perinatol. (2005) 25:173-7. doi: 10.1038/sj.jp.721 1237

17. Hong CR, Han SM, Jaksic T. Surgical considerations for neonates with necrotizing enterocolitis. Semin Fetal Neonatal Med. (2018) 23:420-5. doi: 10.1016/j.siny.2018.0 8.007

18. Thyoka M, De Coppi P, Eaton S, Khoo K, Hall NJ, Curry $\mathrm{J}$, et al. Advanced necrotizing enterocolitis part 1: mortality. Eur J Ped Surg. (2012) 22:008. doi: 10.1055/s-0032-130 6263

19. Hull MA, Fisher JG, Gutierrez IM, Jones BA, Kang KH, Kenny M, et al. Mortality and management of surgical necrotizing enterocolitis in very low birth weight neonates: a prospective cohort study. J Am Coll Surg. (2014) 218:1148-55. doi: 10.1016/j.jamcollsurg.2013.1 1.015 
20. Bazacliu C, Neu J. Necrotizing enterocolitis: long term complications. Curr Pediatr Rev. (2019) 15:115-24. doi: 10.2174/157339631566619031209 3119

Conflict of Interest: The authors declare that the research was conducted in the absence of any commercial or financial relationships that could be construed as a potential conflict of interest.

Publisher's Note: All claims expressed in this article are solely those of the authors and do not necessarily represent those of their affiliated organizations, or those of the publisher, the editors and the reviewers. Any product that may be evaluated in this article, or claim that may be made by its manufacturer, is not guaranteed or endorsed by the publisher.

Copyright (c) 2021 Siahaan, Adriansyah, Sasmita, Fauzi, Dwihantoro and Gunadi. This is an open-access article distributed under the terms of the Creative Commons Attribution License (CC BY). The use, distribution or reproduction in other forums is permitted, provided the original author(s) and the copyright owner(s) are credited and that the original publication in this journal is cited, in accordance with accepted academic practice. No use, distribution or reproduction is permitted which does not comply with these terms. 